\title{
Biomarkers, population-based studies and a proof of principle investigation in pharmacotherapy
}

\author{
P. Falkai • H.-J. Möller
}

Published online: 5 October 2010

(C) The Author(s) 2010. This article is published with open access at Springerlink.com

Dear colleagues,

The current issue of the European Archives of Psychiatry and Clinical Neuroscience offers a selection of key topics currently discussed in psychiatric research ranging from neurobiological findings to population-based as well as proof of principle studies.

The term "biomarkers" is often not used properly in neuroscience as pointed out in the Letter to the Editors by Martins-de-Souza [1]. As outlined in this short article, there is an explosion of the term "biomarker", which is often used for "a differentially expressed" protein discovered as potentially related to some disease in a small sample. The author suggests to be more cautious when using this term and instead suggests to use "potential biomarkers" or "biomarker candidate" as a better and clearer name.

One of those fields with potential new biomarkers is the epidemiology of psychoses. Related to that, Steiner et al. [2] describe in their well-designed paper that in acute paranoid schizophrenia, there might well be reduced T-cell defense and a shift toward B-cell immunity, which normalizes in the response to treatment. Importantly, they point out that in addition to the disease stage or subtype of the illness medication, cigarette smoking and stress are important co-factors.

P. Falkai $(\bowtie)$

Department of Psychiatry und Psychotherapy,

University of Göttingen, von-Siebold-Str. 5,

37075 Göttingen, Germany

e-mail: pfalkai@gwdg.de

H.-J. Möller

Psychiatry Hospital, Ludwigs-Maximilians-University Munich,

Nussbaumstr. 7, 80336 Munich, Germany
Researching cognitive dysfunction in schizophrenia has moved to test circuit-specific tasks in this disorder. The paper by Zilles et al. [3] moves this way identifying subgroups of patients with schizophrenia showing different patterns of selective deficits in working memory components. These deficits are present in tasks requiring only the maintenance of verbal or visuospatial information. In contrast to an obviously global working memory deficit, individual analysis revealed differential patterns of working memory impairments in subgroups of patients with schizophrenia.

Trying to connect brain changes in major psychiatric disorders like depression with pathophysiological mechanisms is desired but difficult. Candidates for hippocampal volume reduction in depressed patients are the neurotrophic factors. Along these lines, Eker et al. [4] found a correlation of serum BDNF levels with hippocampal volumes in first-episode, medication-free depressed patients. This correlation could not be revealed in the control sample, and more interestingly, there was no significant volumetric difference between the depressed patients and the control subjects pointing to a very subtle volumetric change related to BDNF secretion.

Subsequently, two studies were selected using large samples of healthy subjects. In the first study by Moraes et al. [5], the mini-mental state examination (MMSE) was applied in a sample of 2,708 adults, aged 60 years and older. High scores on a depression scale, high scores on a memory complaints scale and low socioeconomic levels were associated with poorer performance on the MMSE. This underlines the importance of some sociodemographic and health variables influencing MMSE performance and furthermore pointing at the increasingly important trajectory between mood disorder and the later development of dementia. 
In the second study by Brand et al. [6], 862 participants completed a series of validated self-report questionnaires assessing sleep, quality of life, depressive symptoms and cognitive-emotional elaboration of pain. For this nonclinical sample of young adults, the bi-directional relation between poor sleep and increased cognitive-emotional elaboration of pain was proven.

In an open proof of principle study by Perugi et al. [7], it was tested whether adjunctive valproate treatment might ameliorate panic disorder symptoms with a lifetime comorbid bipolar disorder or patients otherwise resistant to antidepressants. All patients were evaluated baseline and at least every three month and followed for a period of three years. According to the results, valproate seems to be an effective and a well-tolerated adjunctive treatment in panic disorder patients who are resistant to antidepressant therapy or have bipolar disorders in comorbidity. This supports the hypothesis that the resistance to antidepressants might well be related to mood instability.

Open Access This article is distributed under the terms of the Creative Commons Attribution Noncommercial License which permits any noncommercial use, distribution, and reproduction in any medium, provided the original author(s) and source are credited.

\section{References}

1. Martins-de-Souza D (2010) Is the word 'biomarker' being properly used by proteomics research in neuroscience? Eur Arch Psychiatry Clin Neurosci. doi:10.1007/s00406-010-0105-2
2. Steiner J, Jacobs R, Panteli B, Brauner M, Schiltz K et al. (2010) Acute schizophrenia is accompanied by reduced $\mathrm{T}$ cell and increased B cell immunity. Eur Arch Psychiatry Clin Neurosci. doi:10.1007/s00406-010-0098-X

3. Zilles D, Gruber E, Falkai P, Gruber O (2010) Patients with schizophrenia show deficits of working memory maintenance components in circuit-specific tasks. Eur Arch Psychiatry Clin Neurosci. doi:10.1007/s00406-010-0107-0

4. Eker C, Kitis O, Taneli F, Eker OD, Ozan E, Yucel K, Coburn K, Gonul AS (2010) Correlation of serum BDNF levels with hippocampal volumes in first episode, medication-free depressed patients. Eur Arch Psychiatry Clin Neurosci. doi:10.1007/s00406010-0110-5

5. Moraes C, Pinto JA Jr, Lopes MA, Litvoc J, Bottino CM (2010) Impact of sociodemographic and health variables on mini-mental state examination in a community-based sample of older people. Eur Arch Psychiatry Clin Neurosci. doi:10.1007/s00406-010-0104-3

6. Brand S, Gerber M, Pühse U, Holsboer-Trachsler E (2010) The relation between sleep and pain among a non-clinical sample of young adults. Eur Arch Psychiatry Clin Neurosci. doi:10.1007/ s00406-010-0113-2

7. Perugi G, Frare F, Toni C, Tusini G, Vannucchi G, Akiskal HS (2010) Adjunctive valproate in panic disorder patients with comorbid bipolar disorder or otherwise resistant to standard antidepressants: a 3-year "open" follow-up study. Eur Arch Psychiatry Clin Neurosci. doi:10.1007/s00406-010-0109-y 